\title{
REFLEXÕES METODOLÓGICAS SOBRE O PAPEL DE UM GRUPO DE PESQUISA NA ÁREA DE COMUNICAÇÃO: APRENDENDO NA PRÁTICA
}

\section{METHODOLOGICAL THOUGHTS ABOUT THE ROLE OF A RESEARCH GROUP ON COMMUNICATION: PRACTICE LEARNING}

\section{Kátia Zanvettor Ferreira ${ }^{1}$ \\ Paulo Roxo Barja²}

\begin{abstract}
Resumo: Este trabalho tem como objetivo refletir sobre o papel das práticas de pesquisa em comunicação social para o desenvolvimento de um ensino qualificado nessa área. A partir de um breve histórico do LabCom Univap (que completa 4 anos de atividades), apontamos as principais dificuldades de compor e manter um grupo de pesquisa em uma área com pouca tradição científica. Discutimos sobre a importância de se criar uma cultura de pesquisa no campo de investigação da Comunicação, tão relevante neste momento social em que a informação tem muito valor. Nesse sentido, a estratégia do grupo de pesquisa deve ser ressignificar para os estudantes a ideia de saber que, na pesquisa, deve ser sistematizado para além do senso comum. Concluímos que os pontos positivos do grupo são evidenciar, para alunos e professores, a responsabilidade, disciplina e análise crítica como recursos essenciais para a construção sempre coletiva do saber.
\end{abstract}

Palavras-chave: Comunicação; ensino; LabCom Univap; pesquisa.

Abstract: This paper aims to reflect on the role of research practices in social communication for the development of a qualified teaching in this area. From a brief history of LabCom Univap (about to complete three years of activities), we point out the main difficulties of forming and maintaining a research group in an area with little scientific tradition. We pointed to the importance of creating a culture of research in the field of communication research, so relevant in this social moment in which information is very valuable. In this sense, the research group's strategy must be to reframe for the students the idea of knowing who (in the research) must be systematized beyond common sense. We conclude that the strengths of the group are to evidence, for students and teachers, the responsibility for conducting research and critical analysis as essential resources for building knowledge.

Keywords: Communication; education, LabCom Univap; research.

\section{INTRODUÇÃO}

É voz corrente a afirmação de que estamos inseridos em uma civilização da comunicação. Ora, o ser humano sempre foi por natureza um ser simbólico, ser de linguagem e de comunicação. Comunicar-se, portanto, não é novidade para o humano. Onde está a novidade? Ela só pode estar na multiplicação crescente e acelerada dos meios que o ser humano dispõe para criar, registrar, transmitir e armazenar linguagens e informações (BAYLON; MIGNOT, 1999 apud SANTAELLA, 2001).

\footnotetext{
1 Doutora em Educação. Docente na Universidade do Vale do Paraíba - UNIVAP, SP, Brasil. E-mail: katia.zanvettor@gmail.com.

2 Doutor em Ciências. Docente na Universidade do Vale do Paraíba - UNIVAP, SP, Brasil. E-mail: barja@univap.br.
} 
O Laboratório de Estudo, Pesquisa e Prática em Comunicação, Cultura e Sociedade (LabCom Univap) foi formado no início de 2014, na Faculdade de Ciências Sociais Aplicadas e Comunicação (FCSAC), da Universidade do Vale do Paraíba (Univap). O LabCom Univap propõe estudar a relação entre Comunicação, Cultura e Sociedade, partindo da perspectiva que esses são elementos indissociáveis para a construção de uma sociedade plural e democrática. O objetivo do grupo é refletir e investigar os processos comunicacionais e seus efeitos a partir das relações entre comunicação, discurso e poder, bem como a articulação desses elementos com a cultura, a produção e a divulgação da ciência. Além disso, busca-se discutir no LabCom Univap a construção do sentido na mídia que, o tempo todo, molda valores, constrói desejos, define verdades e reconfigura as relações sociais. É um papel do grupo de pesquisa procurar compreender como esses elementos se materializam nos diferentes produtos de comunicação: televisão, rádio, jornal impresso e online. Mais que um espaço de pesquisa, o grupo é, portanto, um espaço de construção conjunta do saber.

Como observado na epígrafe do texto de Baylon e Mignot (1999, apud SANTAELLA, 2001), vivemos um tempo em que os meios de comunicação são cada vez mais presentes na vida da sociedade. Essa presença se marca não apenas como fonte de informação, mas como expressão de valores, construção de sentidos e identidades e, portanto, a pesquisa em comunicação é, ou deveria ser, um elemento vital para os estudos e compreensão da sociedade e da cultura. Contudo uma das dificuldades encontradas na academia é justamente despertar nos estudantes de comunicação a percepção de que: i) a pesquisa constitui-se em prática essencial de consolidação do conhecimento; ii) precisa ser organizada e sistematizada.

O estudante que procura um curso na área de Comunicação tem um perfil muito conectado com a prática da profissão. Ao entrar na universidade, no entanto, ele se depara com disciplinas teóricas obrigatórias e enfrenta o desafio do aprofundamento teórico em questões relacionadas às ciências sociais aplicadas. Para além dessa velha dicotomia entre teoria contra prática, o grupo de pesquisa pretende apresentar aos participantes um novo modo de abordar os estudos clássicos da Comunicação: justamente mostrando que é na articulação entre teoria e prática que podemos construir conhecimento de forma mais consolidada.

O presente artigo visa discutir o papel das práticas de pesquisa em Comunicação Social e como o seu desenvolvimento pode ser fundamental para a formação diferenciada do aluno de Comunicação, reforçando uma formação plural, transdiciplinar e humana. Para tal, pretendemos refletir sobre a trajetória do LabCom Univap, particularmente sobre o impacto da prática de pesquisa na formação dos alunos da área de Comunicação. 


\section{LabCom UNIVAP: METODOLOGIA}

O LabCom procura trabalhar com uma metodologia que articula atividades práticas e teóricas. Do ponto de vista formativo, o grupo se reúne uma vez por semana para estudar coletivamente textos previamente acordados entre os participantes. Entre os livros e artigos trabalhados, já foram estudados autores como Perseu Abramo, Lúcia Santaella, Pierre Bourdieu e Stuart Hall, entre outros.

No entanto, além da abordagem científica, o grupo também trabalha a partir de textos literários, buscando criar paráfrases e analogias entre esses materiais literários/ficcionais e os estudos teóricos. Essa metodologia, em nossa percepção, favorece a construção do diálogo entre os participante do grupo, ao mesmo tempo que possibilita a percepção diversificada dos participantes sobre o que é pesquisa e como ela pode influir na realidade social.

Prioritariamente, o grupo procura trabalhar de modo articulado as categorias Mídia, Ciência e Cultura, analisadas a partir da perspectiva discursiva, pressupondo que o discurso se constrói na materialidade histórica de uma sociedade. Contudo, como propõe Braga (2011), consideramos que a pesquisa em Comunicação se faz na articulação entre Teoria, Epistemologia e Prática; além disso, pensando a própria Comunicação como ciência humana aplicada, é preciso admitir, já de saída, a impossibilidade de seguir metodologias "prontas e formatadas".

Sabemos que toda discussão teórica, epistemológica e metodológica é importante para a formação de uma "cultura de pesquisa"; e que a obtenção de um bom manejo de perspectivas, conceitos e abordagens diversificados nesse âmbito é parte importante do programa pessoal de formação continuada de todo pesquisador. Mas aqui se trata de outra coisa, mais próxima, mais urgente e mais concreta - que é a oportunidade de usar a própria pesquisa de dissertação ou de tese como campo de prática, de formação de experiência sobre modos de encaminhar a pesquisa e para aprender com seus desafios" (BRAGA, 2011).

No trecho acima, o autor propõe uma reflexão sobre a prática de pesquisa em mestrado e doutorado; ainda que pareça um pouco avançado para as pretensões de um grupo que trabalha basicamente com alunos de graduação, é possível acolher sua proposta de articulação entre teoria e prática como fundamento essencial para a formação de uma cultura científica. Nesse sentido, a partir do segundo ano de existência, o grupo tem buscado alternativas para fomentar ações práticas na área de Comunicação, desenvolvendo produtos comunicativos nas esferas impressas e audiovisual. Algum desses produtos, são o blog do LabCom e as redes sociais do grupo de pesquisa, cujo conteúdo é de inteira responsabilidade dos alunos. Também temos produzidos vídeos de minuto, que disponibilizamos, no canal do youtube do grupo, logomarcas e peças publicitárias. 


\subsection{LabCom UNIVAP: OBJETIVOS}

Para apresentar os objetivos do LabCom, é necessário considerar os aspectos formativos, investigativos e experimentais de um grupo de pesquisa na área de Comunicação. Em primeiro lugar, pretende-se colaborar com a formação de jovens graduandos da Faculdade de Ciências Sociais Aplicadas e Comunicação (FCSAC), da Universidade do Vale do Paraíba (UNIVAP), com experiências colaborativas e que melhorem a sua compreensão sobre a área e futuro campo de atuação, por exemplo, priorizando a investigação dos temas científicos predominantes na imprensa local. Por outro lado, o fomento a essa atividade de pesquisa em nível de iniciação científica também visa contribuir para o desenvolvimento de um olhar científico na área de Comunicação e abrindo um novo leque para atuação acadêmica. Por fim, pretende-se proporcionar experiências laboratoriais, por meio de projetos de extensão, de atividades de cobertura da divulgação da ciência em âmbito regional.

\subsection{DESAFIOS INICIAIS E PERSPECTIVAS}

Ao longo do período inicial de funcionamento do LabCom Univap, um dos desafios encontrados diz respeito ao fato de que não parece haver, na região, uma cultura de valorização do profissional que esteja envolvido em atividades de pesquisa. $O$ relato de alunos participantes aponta para essa falta de reconhecimento que, de certo modo, reflete-se na dificuldade que os estudantes da área encontram para se engajar em atividades de pesquisa, mesmo dentro do ambiente universitário. É mais fácil, por exemplo, encontrar oportunidades para desenvolvimento de atividades técnicoformativas, com o envolvimento na produção de programas para a TV universitária e/ou web rádio.

Tomando esse contexto inicial como ponto de partida para o estabelecimento de rumos de ação, passamos a trabalhar com a perspectiva de que, além de espaço de reflexão e pesquisa, no longo prazo o grupo passe a funcionar, também, como uma agência modelo de Comunicação, divulgando dados cientificos e culturais em parceria com outras faculdades da Univap e mesmo com empresas e organizações de âmbito regional (Vale do Paraíba). Desse modo, o LabCom passa a ser pensado como algo mais amplo que um grupo de estudo e pesquisa, caminhando no sentido de se tornar um grupo capaz de articular a tríplice função da universidade, aliando, em si, os aspectos de ensino, pesquisa e extensão.

Outro desafio coloca-se para o grupo à medida que este se propõe a atuar no campo das Ciências Sociais Aplicadas, ou seja, em contexto mais amplo que o de Comunicação. Desse modo, em princípio o LabCom Univap está aberto à participação não apenas de alunos do curso de Jornalismo como também de estudantes de Moda, Publicidade e Propaganda, Rádio \& TV, Turismo e Administração. Se, por um lado, isso 
implica na tarefa (nada automática) de construir uma linguagem comum, também é verdade que a multiplicidade de perfis tem enriquecido, de modo bastante significativo, as discussões acadêmicas dentro do grupo. O grupo, hoje, agrega professores da área de comunicação, moda, publicidade, artes e engenharia e alunos da área de moda, publicidade e jornalismo.

Por fim, um desafio adicional é a construção da percepção de que o grupo não é meramente um lugar de depósito do conhecimento, ao qual é possível comparecer, periodicamente, apenas para pegar "porções semanais" de enriquecimento teórico. Por ser fruto de construção coletiva, necessariamente o conhecimento acumulado, nas práticas de grupo, passa pelo debate, com abertura para questionamentos e embate de ideias. Em outras palavras, é importante que a prática de pesquisa mantenha clara distância da chamada "educação bancária", tão bem questionada por Paulo Freire (1974); contudo, não é tão fácil, já que os alunos ainda participam de uma cultura em que essa "educação bancária" é predominante.

\section{PESQUISA: PONTOS DE PARTIDA}

Conforme afirma Pierre Bourdieu em seu livro "Sobre a Televisão":

(...) Os jornalistas têm "óculos" especiais a partir dos quais vêem certas coisas e não outras; e vêem de certa maneira as coisas que vêem. Eles operam uma seleção e uma construção do que é selecionado (BOURDIEU, 2001).

Assim como os jornalistas se armam dessas "lentes especiais" para ver os acontecimentos, podemos considerar que os pesquisadores também possuem seu modo particular de enxergar as investigações. No âmbito da Comunicação, Braga (2011) propõe que sejam consideradas três preliminares. A primeira delas:

(...) é o forte consenso atual de que não é possível assumir abstratamente abordagens prévias e fechadas, a serem aplicadas a uma diversidade de pesquisas. Assim, diferentes pesquisas solicitam diferentes aproximações, conforme suas perguntas e objetos; e mesmo táticas metodológicas comprovadas e pertinentes devem ser ajustadas a características concretas do objeto e ao desenho específico da investigação (BRAGA, 2011).

O autor, no entanto, alerta para o fato de que essa característica, nata da área de comunicação, não autoriza o "vale tudo", a improvisação ou, de modo mais geral, a falta de rigor - muito pelo contrário. Defende, também, que fazer ciência é um ato particular diferenciado de outras práticas sociais igualmente importantes, como literatura, arte ou militância política. O objetivo central do pesquisador - objetivo este em que se estabelece sua diferença em relação aos outros atores sociais - é produzir conhecimento, ainda que "esse fazer científico, hoje, no espaço das ciências humanas, não se pretenda puro, nem objetivo, nem neutro" (BRAGA, 2011). 
A segunda preliminar é uma questão histórico-contextual, marcada na Comunicação pela "diversidade de temas, objetos, questões, ângulos, conceitos, paradigmas e teorias que hoje são acionados, conforme as escolas, as áreas de interesse e as linhas de pesquisa" (BRAGA, 2011). Esta possibilidade plural de olhar a comunicação acaba, por sua vez, trazendo outra questão para o modo operante da pesquisa na área. Trata-se da terceira preliminar, que seria evitar impor aos estudantes as preferências teórico-metodológicas que predominam dentro do grupo ou, mais especificamente, entre os professores pesquisadores. Ainda, de acordo com o autor, "tais preferências não devem "se abater" sobre os estudantes, nem de modo autoritário nem em desconsideração de necessidades específicas de sua pesquisa" (BRAGA, 2011).

Lembramos que a centralidade dos Meios de Comunicação no contexto contemporâneo amplia, ainda, o diálogo da pesquisa em Comunicação em áreas do conhecimento não tão próximas e, segundo Santaella (2001), essas características apontam para a complexidade em que a pesquisa de comunicação está inserida na atualidade.

\begin{abstract}
Um crescimento tão acelerado das bases reais de uma área de conhecimento só pode produzir confusões e dificuldades de compreensão, inclusive naquelas que trabalham na área e nela pesquisam. As afirmações de que a complexidade da comunicação advém de sua natureza inter, multi e mesmo transdisciplinar já se tornaram um truísmo (SANTAELLA, 2001, p. 14).
\end{abstract}

Em resumo, podemos afirmar que a pesquisa em Comunicação requer abordagens abertas: não há uma "receita de pesquisa". A diversidade de assuntos tratados implica na diversidade de estratégias; sendo assim, um pesquisador não deve adequar um tema às suas preferências teóricas. Ao contrário: cada tema demanda abordagens específicas.

\title{
4. PRIMEIROS RESULTADOS: EU-PESQUISADOR
}

Uma das atividades que consolida o papel do LabCom Univap, entre os alunos de graduação da FCSAC, é justamente a seleção anual do grupo de pesquisa. Nela, os alunos interessados em participar são convidados a escrever um texto sobre o que entendem por "pesquisa em Comunicação" e, após uma primeira seleção, convocados para entrevistas presenciais. Ao serem indagados a respeito de qual a motivação para ingresso no grupo de pesquisa, os candidatos costumam responder, de modo geral, que "querem aprender mais com as reuniões do grupo", respostas que indiciam que o aluno ainda espera encontrar seu "cheque" de sabedoria na "educação bancária" pressuposta. No entanto, posteriormente à sua entrada no grupo, uma análise das falas dos alunos integrantes mostra que, com a vivência real no grupo, eles tendem a mudar de posição, passando a valorizar mais o processo de reunião e o aprendizado construído.

$\mathrm{Na}$ declaração de uma das participantes, após um ano de atividades junto ao 
LabCom Univap, a agora jornalista aponta o impacto do grupo na sua percepção da construção do conhecimento e, também, da profissão:

Hoje, consigo vivenciar a importância dessa experiência para o meu dia a dia profissional. Tento aplicar o prazer da pesquisa nos trabalhos diários, claro, sem deixar de lado a busca pelo aprendizado. Infelizmente, o conhecimento teórico e a valorização da pesquisa na área de comunicação são escassos na realidade de mercado que vivemos. Acabei de me formar, mas sinto o desejo de continuar me aprofundando neste ramo. Ano passado também fui aluna pesquisadora do LabCom Univap e, sem dúvida, essa experiência despertou em mim o desejo de seguir os caminhos do universo acadêmico (aluna Maiara, participante do LabCom Univap, em 2014).

A declaração da aluna sugere que ela tem uma nova percepção da pesquisa, como algo aplicado e que pode, portanto, mostrar-se útil no dia a dia. Além disso, transparece em sua declaração o fato de que, para ser uma pesquisadora, o mais importante é estar interessada em investigar, independentemente de qualquer valorização "na realidade de mercado que vivemos".

Essa percepção da aluna dialoga, diretamente, com o debate levantado acima, sobre as três diferentes dimensões da pesquisa em comunicação. Nesse caso, acreditamos que a aluna pode ser inserida em um modo de "pensar como pesquisadora" e que o sujeito pesquisador está em relação com o mundo, dialoga com o mundo, mas estabelece conexão com ele a partir de um lugar específico, o lugar do estudo, da investigação e do rigor (BRAGA, 2011).

$\mathrm{Na}$ fala de outra aluna, o comentário segue a mesma perspectiva a respeito da pesquisa como algo a ser levado para a vida. Ou seja, a pesquisa também aqui altera o modo como a aluna-jornalista pensa o mundo e como ela irá se relacionar com ele a partir dessa experiência:

Eu me formei e continuo participando do LabCom Univap, com o objetivo de ingressar na especialização, mestrado e futuramente doutorado. O LabCom Univap fez toda a diferença na minha caminhada profissional e consigo entender completamente que depois da pesquisa eu me tornei uma jornalista com visões distintas da sociedade, ciência e comunicação (aluna Natalee, participante do LabCom Univap 2014/2015).

Esta fala também faz conexão com a primeira dimensão da reflexão sobre a pesquisa e dialoga com a segunda dimensão, a pluralidade de caminhos, teorias e objetos do campo da comunicação. Ao dizer que "consigo entender completamente que depois da pesquisa eu me tornei uma jornalista com visões distintas da sociedade, ciência e comunicação", a jornalista está assumindo uma posição de pesquisadora em que olha para a sua carreira de uma forma diferente, tornando-se, em si, a própria carreira um elemento em construção. Logo, percebe-se que houve um entendimento que a pesquisa serve para além dos bancos acadêmicos. Altera sua percepção e relação com o mundo e pode, paralelamente ao projeto de carreira acadêmica, formar um profissional melhor. 
Em outra fala, de outro participante, o argumento se repete e podemos, de novo, constatar a importância do grupo para a tomada de consciência do "ser profissional". Neste caso, trata-se de um participante mais antigo e que acompanhou o grupo desde a sua primeira formação e, portanto, aponta para o impacto do grupo não apenas como profissional, mas como cidadão, indicando um impacto mais profundo do grupo na subjetividade do sujeito. A fala ainda aponta que os trabalhos do grupo sempre estabeleceram conexão com as demais disciplinas da faculdade, indicando, ainda, a pertinência complementar formativa dos estudos do grupo:

Participar do Labcom durante os três anos de faculdade que estive na Univap foi muito importante para ampliar minha formação crítica enquanto comunicólogo e cidadão, por meio do espaço de debate que criamos nesse período utilizando textos que nem sempre conseguimos estudar nas disciplinas curriculares. O Labcom foi essencial também ao mostrar que é possível fazer ciência, pesquisar e quanto é fascinante e necessário para a academia, o mercado e a sociedade (aluno Jader, participante Labcom 2014/2015/2016).

Outra fala que chama atenção cita a ausência das oportunidades de pesquisar e ter maior contato com este universo no ambiente acadêmico, justamente o local ideal para este contato:

A carência da pesquisa em comunicação é nítida na realidade com a qual tive contato no Vale do Paraíba. Tive o contato com a pesquisa nos últimos anos da graduação, antes não havia incentivos que atraíssem os alunos pois, infelizmente, hoje o foco está totalmente voltado para o mercado. Gostaria de ter tido contato com a pesquisa logo no início da faculdade, mas guardo essa vontade para o futuro (Natalee, LabCom Univap 2014/2015).

Esta percepção sinaliza para a importância do Labcom: sua implantação e trajetória marcou, positivamente, a vida dos alunos envolvidos. Mostra que o Labcom, de um modo ou de outro, tem, de fato, cumprido o papel formativo ao qual se propôs no início da sua caminhada. Considera-se, ainda, que as falas apontam que grupos de pesquisa são espaços importantes para sistematizar práticas inovadoras e aproximar os estudantes de uma nova abordagem, possibilitando uma nova relação com 0 aprendizado não necessariamente para a formação de novos pesquisadores, mas também, e talvez com prioridade, para a formação de profissionais críticos.

\section{CONCLUSÃO}

O processo de envolvimento dos estudantes com o grupo de pesquisa configurase como essencial para que estes efetivem uma transição na forma como encaram o próprio desenvolvimento do conhecimento. Conhecer de perto a atividade de pesquisa e estimular os alunos a desenvolver projetos que integrem teoria e prática pode estimular para uma mudança de posição frente ao conhecimento.

De uma situação inicial, que pode ser descrita como "quero saber", para outra, mais atuante e próxima do "saber como saber", são os primeiros resultados que 
podemos acompanhar com o desenvolvimento do grupo de pesquisa. A própria ideia de que o grupo está sendo construído com a ajuda dos alunos tem impactado no resultado geral do trabalho.

A escolha metodológica de não priorizar uma única linha de pesquisa, de valorizar a participação prática com o desenvolvimento de produtos e a não imposição de um tema de pesquisa ou metodologia, deixando para o aluno selecionar e escolher seu próprio caminho tem se mostrado uma escolha acertada.

Ainda há inúmeras dificuldades para serem enfrentadas no grupo de pesquisa e muitas delas são de natureza econômica, política e social: particularmente, é difícil enfrentar o fato de que muitos alunos acabam desistindo da pesquisa por não conseguirem conciliá-la com a necessidade do trabalho e do estudo. Precisamos lembrar que o Labcom se desenvolve no interior de um curso superior noturno e, só por isso, nem sempre a pesquisa voluntária é um caminho possível de escolha na realidade do corpo discente.

Acreditamos, porém, que oportunizar ao menos a possibilidade de participar já é um processo relevante para o desenvolvimento de uma nova relação com o saber e impacta positivamente na formação dos estudantes - não apenas nos que participam diretamente do grupo em questão, como também naqueles que fazem parte de suas redes de contato. Concluímos, assim, que o ponto positivo do grupo está justamente em mostrar, a partir de uma prática contínua e coletiva, que fazer pesquisa é assumir a responsabilidade pela construção ativa do seu conhecimento.

\section{REFERÊNCIAS}

BOURDIEU, P. Sobre a televisão. Rio de Janeiro: Jorge Zahar Editora, 2001.

BRAGA, J. L. A Prática da pesquisa em comunicação: abordagem metodológica como tomada de decisões. Revista da Associação Nacional dos Programas de PósGraduação em Comunicação E-compós, Brasília, v.14, n.1, 2011.

FREIRE, P. Pedagogia do oprimido. São Paulo: Editora Paz e Terra, 1974, 253p.

SANTAELLA, L. Comunicação e Pesquisa: projetos para mestrado e doutorado. São Paulo: Hacker Editores, 2001. 